\title{
Microhardness studies in gel-grown ADP and KDP single crystals
}

\author{
S SENGUPTA and S P SENGUPTA \\ Department of Materials Science, Indian Association for the Cultivation of Science, \\ Jadavpur, Calcutta 700032, India \\ MS received 7 August 1991; revised 13 January 1992
}

\begin{abstract}
Microhardness studies were carried out on (100) faces of gel-grown ADP and KDP single crystals. Slip lines were observed on (100) face of ADP crystal at the corners of the impressions. Microcracks around the indentation were found on (100) face of KDP crystal from $10 \mathrm{~g}$ load which spread out as the load increased. Vickers hardness number $H_{r}$ decreased with increase in load. $\Delta H_{\mathrm{r}}$ at $50 \mathrm{~g}$ load for solution-grown crystals and gel-grown crystals (present case) was determined. Work hardening index $n$ for both ADP and KDP crystals was less than 2 showing soft-material characteristics. Using Wooster's empiricai relation, values of $C_{11}$ from hardness were calculated and found to be close to the reported ones.
\end{abstract}

Keywords. Microhardness; elastic constant; anmonium dihydrogen orthophosphate; potassium orthophosphate.

\section{Introduction}

Single crystal study of ammonium dihydrogen orthophosphate (ADP) and potassium dihydrogen orthophosphate (KDP) has gained considerable importance in recent years because of their important ferroelectric, piezoelectric and electro-optic properties.

As regards mechanical properties, hardness testing provides useful information on the strength and deformation characteristics of materials (Mott 1956) and is correlated with other mechanical properties like elastic constants (Wooster 1953) and yield stress (Westbrook 1958). Meyer (1951) established a relationship between indentation hardness and plastic and work-hardening capacity of a material. The hardness of a material is defined (Ashby 1951) as the resistance it offers to the motion of dislocations, deformation or damage under an applied stress. The most common measurement of hardness is the indentation type. Hardness test methods are used to determine the stress needed to produce plastic flow in the brittle material. It measures the mean contact pressure when a spherical, a conical or a pyramidal indentor is pressed on to the surface of a flat specimen, thus providing a simple and non-destructive means of assessing the resistance of the material to plastic deformation. The general definition of indentation hardness is the ratio of the applied load to the surface area of indentation. The relation between the load and size of indentation, is given by Meyer's law as $p=\mathrm{ad}^{n}$ where $p$ is load in $\mathrm{kg}, d$ the diameter of recovered indentation in $\mathrm{mm}$ and $a$ and $n$ are constants for a given material. The Meyer index number $n$ gives the value of work-hardening index. The behaviour of indentation hardness at low loads has been a controversial subject. In the light of these, hardness measurements have been made on (100) face of gel-grown ADP and KDP crystals in the load region of 5 to $100 \mathrm{~g}$ for ADP and 5 to $50 \mathrm{~g}$ for KDP. The literature is scarce and the studies on the (100) face of gel-grown ADP are being done for the first time. 


\section{Experimental}

The crystal growth experiments were performed by slow diffusion in silica gel medium at room temperature (Sengupta et al 1990). The microhardness of ADP and KDP crystals was determined using mhp 160 microhardness tester fitted with Vickers diamond pyramid indentor and attached to a Carl-Zeiss (Jenavert) incident light research microscope.

For the static indentation test, load $p$ varying from 5 to $100 \mathrm{~g}$ were applied on the selected (100) faces of the crystals over a fixed interval of time $(10 \mathrm{~s})$, and removed. The indented impressions were approximately square. The surfaces were indented at different sites. Diagonal lengths of the indented impressions obtained at various loads were measured using a calibrated micrometer attached to the eye piece of the microscope. Several indentations were made on each sample. The average value of the diagonal lengths of the indentation mark for each load was used to calculate the hardness. The Vickers microhardness number $H_{v}$ was calculated using the relation $H_{v}=1.8544\left(p / d^{2}\right) \mathrm{kg} \mathrm{mm}^{-2}$, where $p$ is the applied load in $\mathrm{kg}$ and $d$ the average diagonal length of the Vickers impression in $\mathrm{mm}$ after unloading.

\section{Results and discussion}

Figure 1 shows the indentation marks on the (100) face of ADP crystal at $50 \mathrm{~g}(\mathrm{~b})$ and $100 \mathrm{~g}(\mathrm{a})$ load. Slip lines were observed at each corner of the impression at $100 \mathrm{~g}$ load. Maximum indentor load applied for ADP was $100 \mathrm{~g}$. Figures 2(a, b, c) show the indentation marks on (100) face of KDP at 10, 25 and $50 \mathrm{~g}$ load. Maximum indentor load applied for KDP was $50 \mathrm{~g}$, because microcracks were observed around the impression. Cracks initiate at $10 \mathrm{~g}$ load (figure $2 \mathrm{a}$ ) and tend to propagate with the

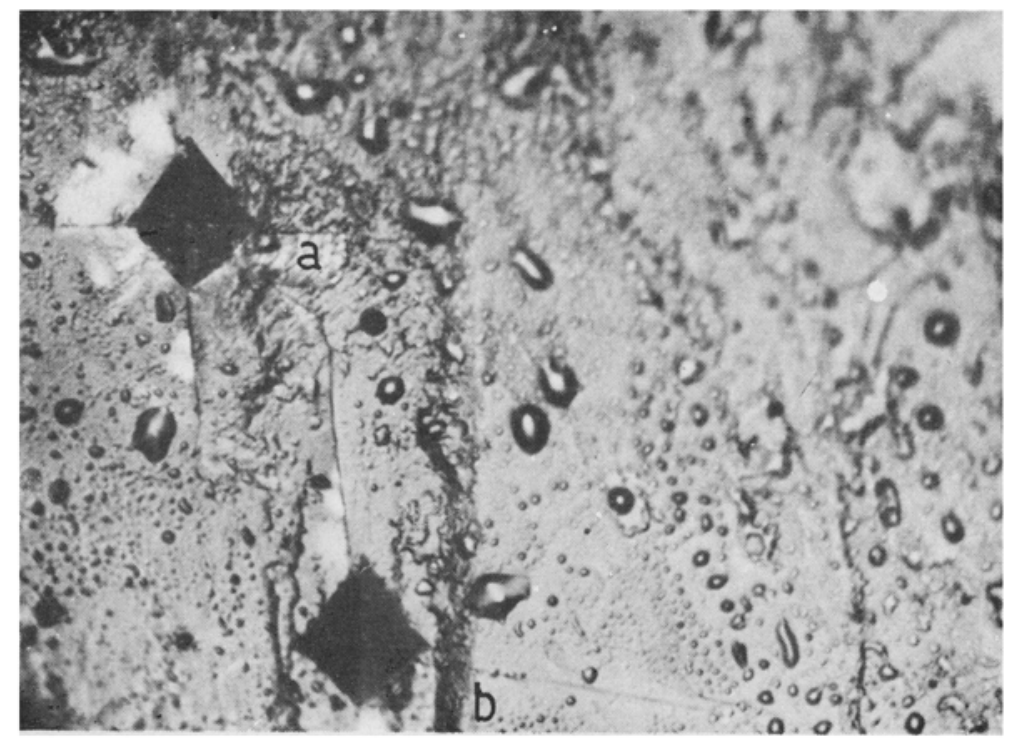

Figure 1. Indentation mark on the (100) face of gel-grown ADP crystal by Vickers indentor $(\times 80)$ for (a) $100 \mathrm{~g}$ load, (b) $50 \mathrm{~g}$ load. 
increased load of $50 \mathrm{~g}$, as may be evident from figure 2(c). This implies that the increased hardness of KDP crystals, as also reflected from the increased value of hardness number in figure 3, shows the variation of hardness with indentor load. This variation for solution-grown ADP and KDP crystals, reported by Anbukumar et al (1986) is also plotted on the same graph (symbol $\Delta$ ). $\Delta H_{v}$ at $50 \mathrm{~g}$ load for solution-grown and gel-grown crystals is determined from the graph. It turns out to be $31.2 \mathrm{~kg} / \mathrm{mm}^{2}$ for ADP and $12 \mathrm{~kg} / \mathrm{mm}^{2}$ for KDP. This shows that the hardness number slightly varies in the same crystal grown by different techniques. The microhardness is found to decrease with increase of indentor load (from 5 to $25 \mathrm{~g}$ ) for both ADP and KDP, and remains unaffected beyond this load. With gradual
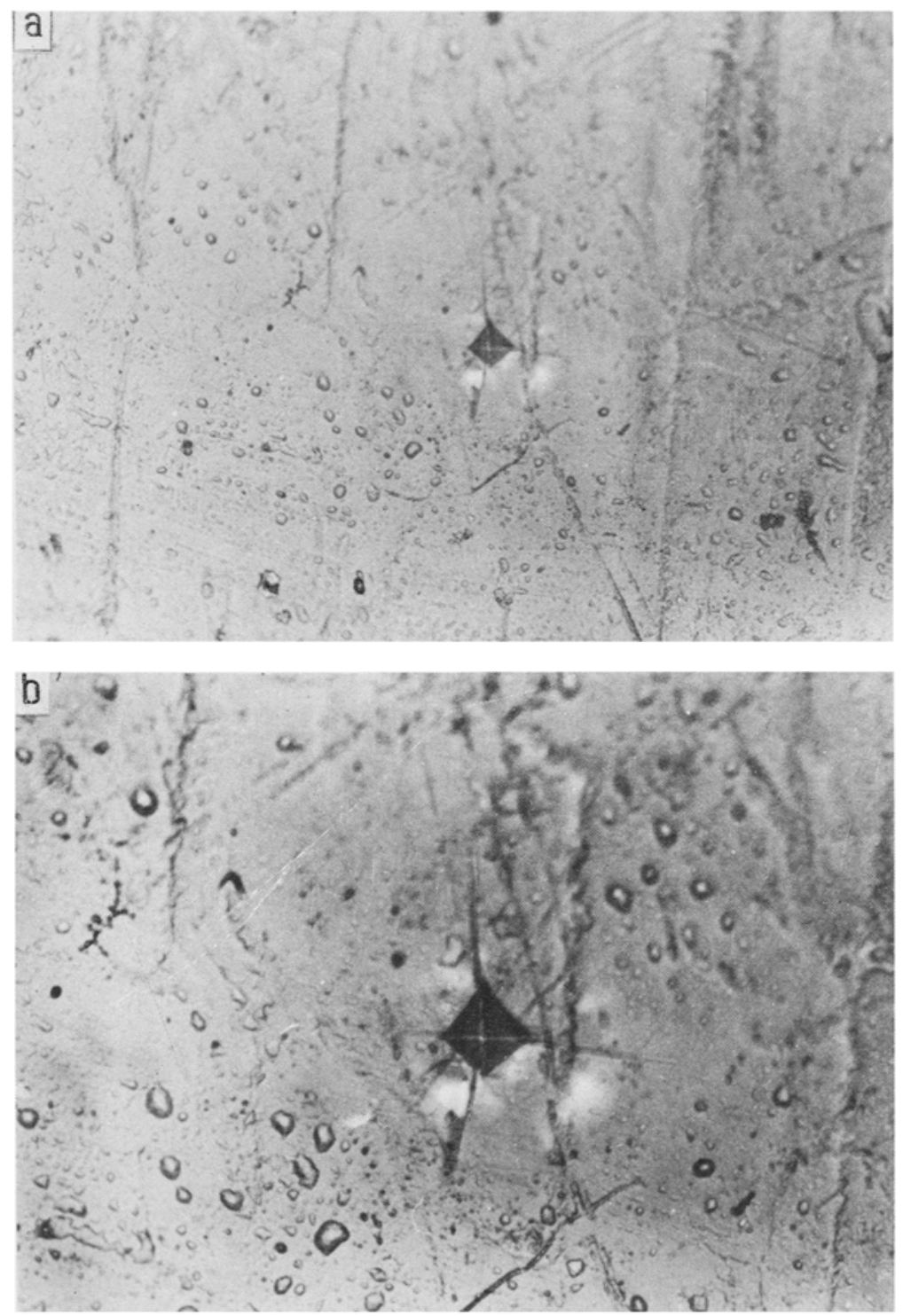

Figure 2. a-b. For caption, see p. 336 . 


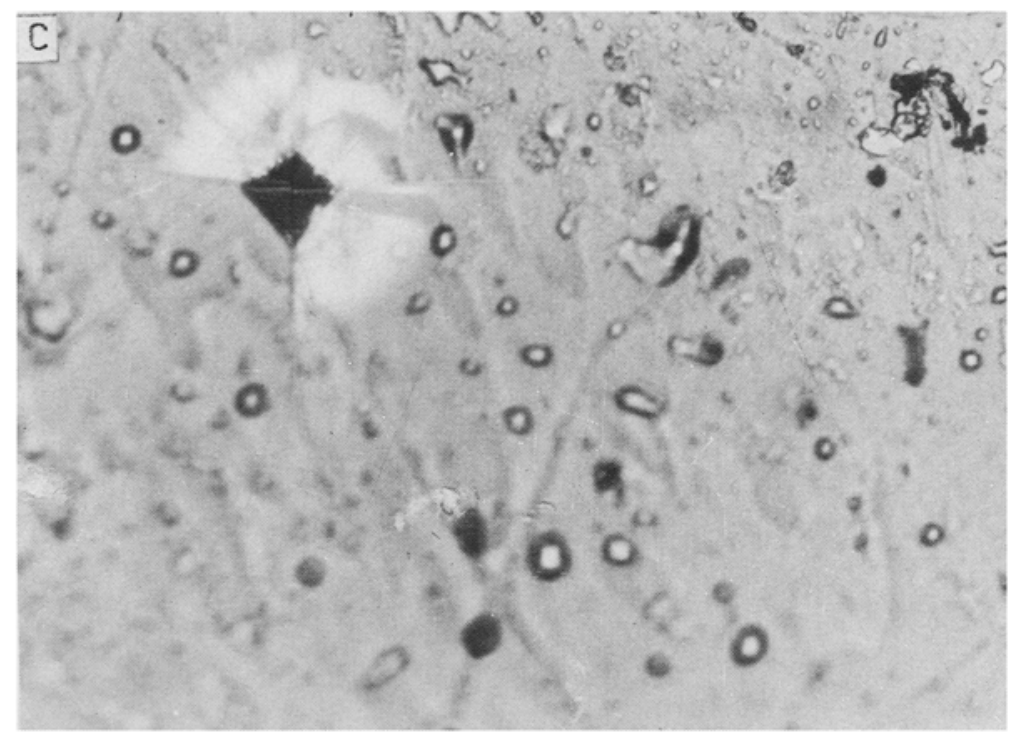

Figure 2. Indentation mark on the (100) face of gel-grown KDP crystal by Vickers indentor ( $\times 80$ ) for (a) $10 \mathrm{~g}$ load, (b) $25 \mathrm{~g}$ load, (c) $50 \mathrm{~g}$ load.

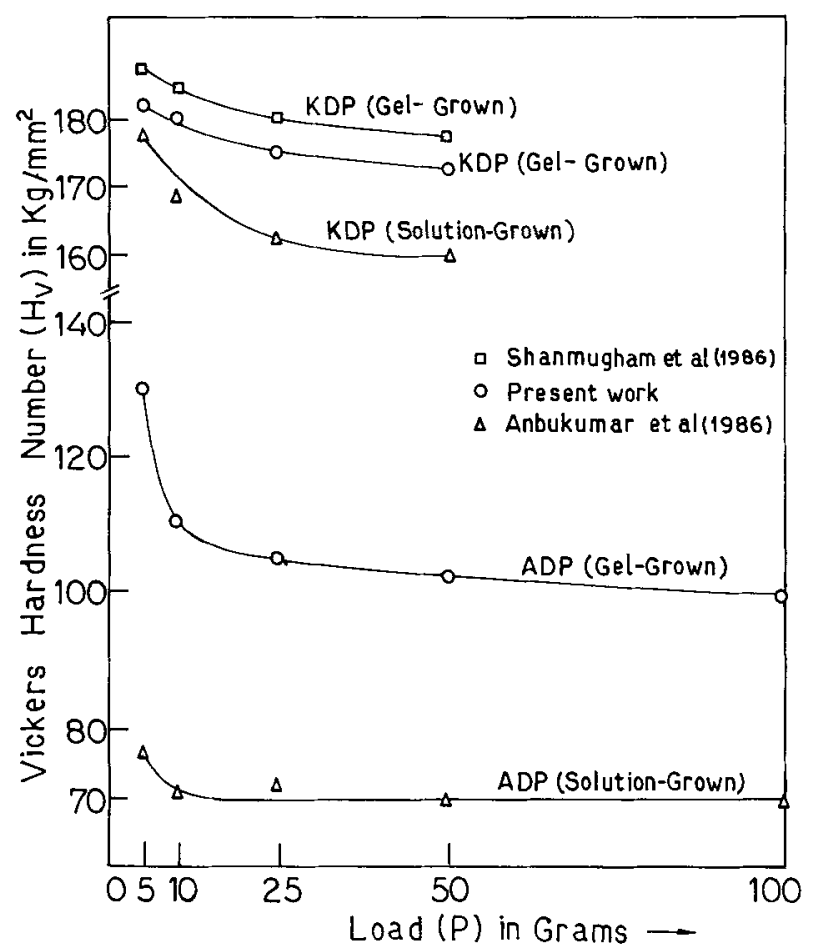

Figure 3. Graph showing variation of microhardness $H_{v}$ with load $P$.

increase of the applied stress, the elastic limit of the material can be exceeded and the specimen will not restore its original shape on removal of the stress. In the present case, microhardness number $H_{v}$ was $99 \mathrm{~kg} / \mathrm{mm}^{2}$ at $100 \mathrm{~g}$ load for ADP crystal and $172.5 \mathrm{~kg} / \mathrm{mm}^{2}$ at $50 \mathrm{~g}$ load for KDP crystal. This value is also very close to the value 


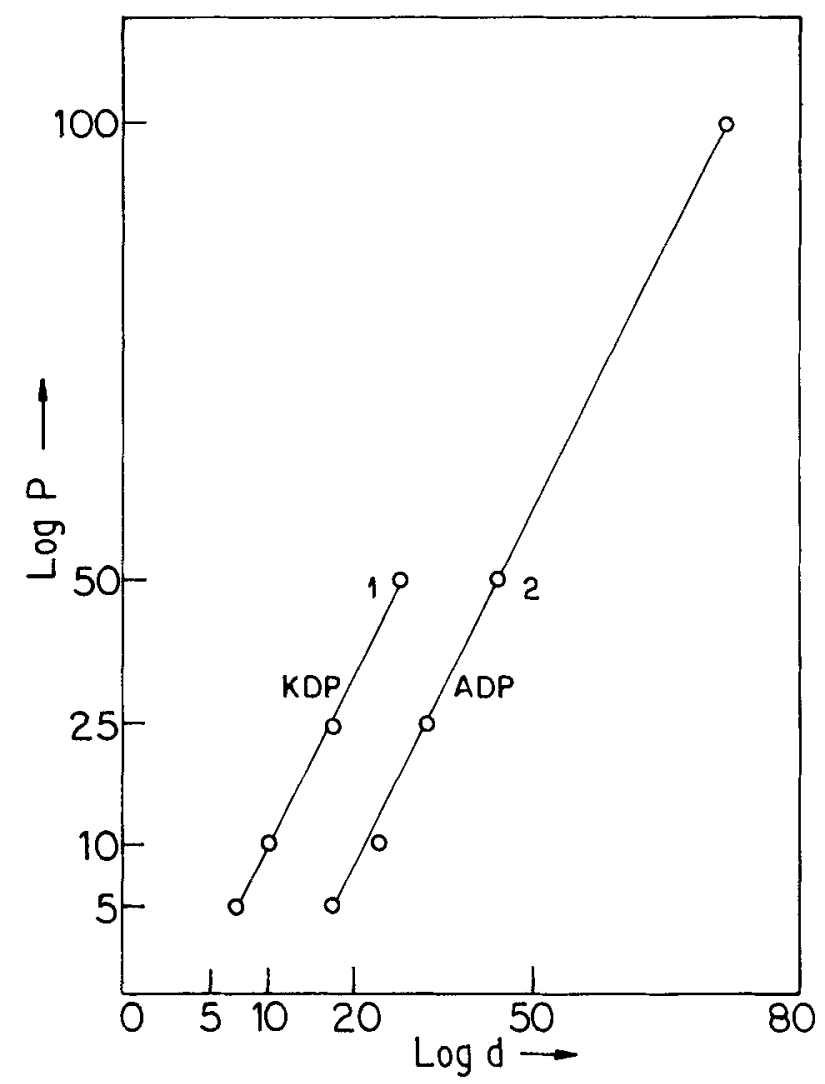

Figure 4. Log-log plot of Meyer for (1) KDP and (2) ADP.

Table 1. Calculated values of $n$ and $C_{11}$.

\begin{tabular}{|c|c|c|c|c|c|}
\hline \multirow[b]{2}{*}{ Crystal } & \multicolumn{2}{|c|}{$\begin{array}{l}\text { Work hardening } \\
\text { index }(n)\end{array}$} & \multicolumn{2}{|c|}{$\begin{array}{l}\text { Elastic stiffness } \\
\text { coefficient }\left(C_{11}\right)\end{array}$} & \multirow[b]{2}{*}{ Reference } \\
\hline & $\begin{array}{l}\text { Calculated } \\
\text { values } \\
\text { (gel-grown) }\end{array}$ & $\begin{array}{l}\text { Reported } \\
\text { values* } \\
\text { (solution } \\
\text { grown) }\end{array}$ & $\begin{array}{l}\text { Calculated values } \\
\text { from relation } \\
C_{11}=H^{7 / 4} \text { in } \\
\text { C.G.S. units }\end{array}$ & $\begin{array}{c}\text { Reported } \\
\text { values }{ }^{+} \\
\text {in C.G.S } \\
\text { units }\end{array}$ & \\
\hline ADP & 1.991 & 1.941 & $3.045 \times 10^{11}$ & $4.725 \times 10^{11}$ & $\begin{array}{l}\text { *Anbukumar } \\
\text { et al (1986) }\end{array}$ \\
\hline KDP & 1.975 & 1.917 & $5.119 \times 10^{12}$ & $6.235 \times 10^{11}$ & $\begin{array}{l}{ }^{+} \text {Simmons and } \\
\text { Wang (1971) }\end{array}$ \\
\hline
\end{tabular}

$177 \mathrm{~kg} / \mathrm{mm}^{2}$ reported by Shanmugham et al (1986) in the measurement of $H_{v}$ of gel-grown KDP crystal.

The log-log plot drawn between $d$ and $p$ yields a straight line (figure 4). The slope of the line gives the value of $n$, the work-hardening index. Table 1 shows the values for ADP and KDP.

Following Wooster's empirical relation $\left(C_{11}=H^{7 / 4}\right)$ between elastic stiffness coefficient and hardness of a crystal (Wooster 1953), we calculated the values of $C_{11}$ 
(averages of $C_{11}$ and $C_{33}$ ) for both ADP and KDP crystals. The calculated values were found to approximate to the reported results (Simmons and Wang 1971) (table 1).

\section{Conclusion}

On the basis of careful investigations on various substances, Onitsch (1947) and Hanneman (1941) had shown that the value of $n$ comes out to be 1 to 1.6 for hard material and more than 1.6 for soft material, and that microhardness decreases with increase of load when $n<2$. The decrease in $H_{v}$ with load, observed in the present case, is in agreement with the theoretical prediction.

Hardness values of solution-grown crystals are less than $H_{v}$ of gel-grown crystals (as shown in figure 3). This implies that solution-grown crystals are softer than gel-grown crystals which apparently contain more defects. The major problem associated with the gel method lies in the poor control over supersaturation, which varies in the gel from one point to another. Near the growing interface, it is about the same as in solution. Far from the interface, however, the values of the supersaturation must be much higher in gel than in solutions causing fluctuations in growth rate and thereby inducing more crystalline defects. The gel inclusion is also responsible for the generation of defects in these crystals. Further, it has been observed that the hardness value of KDP crystals is greater than that of ADP crystals. This could be attributed to the differences in their molecular structures. Crystallographically, both $\mathrm{ADP}$ and KDP are similar in $\mathrm{H}_{2} \mathrm{PO}_{4}$ network. In ADP crystals, $\mathrm{N}-\mathrm{H} \ldots \mathrm{O}$ bond occurs between ammonium and phosphate groups, whereas KDP structure is a polar structure consisting of $\mathrm{K}^{+}$and $\mathrm{H}_{2} \mathrm{PO}_{4}^{-}$ions. The ionic bonding between $\mathrm{K}^{+}$and $\mathrm{H}_{2} \mathrm{PO}_{4}^{-}$ions in KDP is stronger than $\mathrm{N}-\mathrm{H}$... O bond existing in ADP molecules. As a result, KDP shows increased hardness.

The hardness measurements may be useful in indicating the order of magnitude to be expected for the elastic constant in a new material.

\section{Acknowledgements}

The work was done under a research project sanctioned by the Council of Scientific and Industrial Research (CSIR), New Delhi. One of the authors (SSG) is thankful to Dr Tanusree Kar for helpful suggestions and also to CSIR for a research fellowship.

\section{References}

Ashby N A $1951 \mathrm{~J}$. Nucl. Engg. 633

Anbukumar S, Vasudevan S and Ramaswamy P 1986 J. Mater. Lett. 5224

Hanneman M 1941 Metallurgia Manchu. 23135

Mott B W 1956 Micro-indentation hardness testing (London: Butterworths) pp 206

Meyer 1951 Some aspects of the hardness of metals, Ph D Thesis, Dreft

Onitsch E M 1947 Mikroskopie 2131

Shanmugham M, Gnanam F D and Ramaswamy P 1986 J. Mater. Sci. Lett. 5174

Sen Gupta S, Kar T and Sen Gupta S P 1990 J. Mater. Sci. Lett. 9334

Simmons $G$ and Wang $\mathrm{H} 1971$ Single crystal elastic constant and calculated aggregate properties (Massachusetts: MIT) vol. 2, p. 114

Westbrook J H 1958 Flow in rock salt structure (Report 58-RL 2033 of the G E Research Laboratory, USA)

Wooster W A 1953 Rep. Progr. Phys. 1662 